\title{
PERANCANGAN NOZZLE DAN SISTEM PERPIPAAN PADA TURBIN PELTON SKALA LABORATORIUM
}

\author{
AMIR $^{1}$, RIKI CANDRA PUTRA ${ }^{2}$, HILMAN RIZKY SAPUTRA ${ }^{3}$ \\ Program Studi Teknik Mesin, Fakultas Teknik, Universitas Muhammadiyah Tangerang \\ Jl. Perintis Kemerdekaan I/33 Cikokol-Tangerang \\ E-Mail :amirduta815@gmail.com
}

\begin{abstract}
ABSTRAK
Fungsi zat aditif untuk menyempurnakan proses kimia pembakaran, membersihkan mesin dari semua timbunan kotoran, baik itu pada intake valve, port fuel injector dan combuction chamber, mencegah korosi pada saluran dan tangki,tentunya kinerja mesin akan meningkat. Zat aditif yang akan digunakan pada pengujian ini adalah bullsone shot motorbike.Dengan beberapa kelebihan dari Zat Aditif maka perlu dilakukannya pengujian performa terhadap kendaraan Pengujian performa campuran pertalite dengan zat aditif yang dilakukan salah satunya diharapkan dapat mengetahui seberapa besar pengaruh terhadap daya dan torsi pada mesin. Daya merupakan kemampuan kendaraan untuk mencapai kecepatan tertinggi dalam waktu tertentu, sedangkan torsi merupakan gaya atau kemampuan mesin untuk menggerakan kendaraan dari posisi diam sampai berjalan. Dengan menggunakan bahan bakar pertalite dan campuran zat aditif sebesar $100 \mathrm{ml}$ menghasilkan daya dan torsi yang lebih tinggi dibandingkan dengan menggunakan pertalite murni. Peningkatan pada torsi maksimum sebesar 1,02 Kg.m dan peningkatan pada daya maksimum sebesar 10,13 $P S$.
\end{abstract}

Kata Kunci : Zat aditif; Performa engine; Daya; Torsi.

\begin{abstract}
The function of additives is to improve the chemical combustion process, clean the engine from all dirt deposits, be it on the intake valve, fuel injector port and combustion chamber, prevent corrosion in the channel and tank, of course, the engine performance will increase. The additive that will be used in this test is a bullsone shot motorbike. With several advantages of the Additive Substance, it is necessary to do a performance test on the vehicle. The performance test of a mixture of pertalite with additives is carried out, one of which is expected to find out how much influence it has on the power and torque of the engine. Power is the ability of the vehicle to reach the highest speed in a certain time, while torque is the force or ability of the engine to move the vehicle from rest to running. Using pertalite fuel and a mixture of additives of $100 \mathrm{ml}$ produces higher power and torque than using pure pertalite. An increase in maximum torque of $1.02 \mathrm{Kg} . \mathrm{m}$ and an increase in maximum power of 10.13 PS.
\end{abstract}

Keywords: Additives, Engine Performance, Power, Torque

\section{PENDAHULUAN}

Motor pembakaran dalam (Internal Combustion Engine) merupakan pesawat kalori yang mengubah energi kimia dari bahan bakar menjadi energi mekanis. Energi kimia yang berasal dari bahan bakar yang bercampur dengan udara terlebih dahulu diubah menjadi energy panas/termal melalui pembakaran, sehingga temperatur dan tekanan gas pada saat pembakaran di dalam silinder meningkat. Gas hasil pembakaran yang bertekanan tinggi di dalam silinder akan berekspansi dan mendorong piston bergerak translasi sehingga menghasilkan gerak rotasi poros engkol (crankshaft) sebagai keluaran mekanis dari motor.

Pada motor pembakaran dalam hal yang perlu diperhatikan yaitu pada bahan bakar yang digunakan, bahan bakar merupakan kebutuhan utama dalam proses pembakaran pada mesin, mengakibatkan bahan bakar menjadi kebutuhan penting pada kehidupan sehari-hari masyarakat. Pemakaian bahan bakar fosil secara besar-besaran dan terus menerus dapat mengakibatkan kelangkaan pada bahan bakar itu sendiri. Selain itu pemakaian bahan bakar fosil ini telah memberikan dampak negatif terhadap lingkungan. Kualitas udara semakin menurun akibat asap pembakaran bahan bakar minyak bumi yang mengandung gas-gas berbahaya seperti CO2, NOx dan UHC (unburn hydrocarbon), juga unsur metalik seperti timbal (pb). Kemudian efek gas rumah kaca yang disebabkan oleh gas $\mathrm{CO} 2$ hasil pembakaran minyak bumi yang mengakibatkan pemanasan global (global warming).

Emisi gas buang terbentuk akibat pembakaran campuran dan bahan bakar yang tidak sempurna didalam mesin sehingga membentuk sifat gas beracun berupa gas karbonmonoksida, gas hidrokarbon, dan lain sebagainya. Para pengguna kendaraan bermotor dapat melakukan tindakan 
prepentive terhadap saluran bahan bakarnya dengan menambahkan zat aditif yang bisa ditambahkan dalam bahan bakar. Ada beberapa zat aditif yang bisa ditambakan kedalam bahan bakar dimana zat tersebut mempunyai fungsi untuk meningkatkan kinerja dari mesin kendaraan (Saputra et.al.,2013)

Kandungan zat aditif itulah yang dapat membuat bahan bakar meningkat menilai oktannya dan dari perubahan itu menjadikan tingkat pembakaran menjadi lebih sempurna sehingga berpengaruh terhadapat kinerja mesin dan emisi gas buang. Maka dengan bahan bakar berkualitas kita dapat memperoleh kesempurnaan pembakaran pada mesin selain itu zat aditif juga memiliki kemampuan untuk membersikan saluran bahan bakar sehingga memudahkan proses pembakaran. Dalam penelitian ini akan mencoba menganalisa bahan bakar pertalite yang memiliki angka oktan dan menambahkan zat aditif octan boaster.

Dengan beberapa kelebihan dari octane boster maka perlu dilakukannya pengujian performa terhadap kendaraan. Pengujian performa campuran pertalite dengan octane boster yang dilakukan salah satunya diharapkan dapat mengetahui seberapa besar pengaruh terhadap daya dan torsi mesin. Daya merupakan kemampuan kendaraan untuk mencapai kecepatan tertinggi dalam waktu tertentu, sedangkan torsi merupakan gaya atau kemampuan mesin untuk menggerakan. Berdasarkan uraian di atas, maka penulis akan mengangkat topik mengenai "pengaruh penambahan aditif octane booster terhadap campuran pertalite untuk meningkatkan unjuk kerja mesin motor automatic satu silinder $125 \mathrm{cc}$.

\section{METODOLOGI PENELITIAN}

Adapun metode penelitian yang dilakukan dalam proses penelitian pada pembangkit listrik tenaga bayu tipe vertikal diantaranya :

1) Studi Lapangan

Mempelajari turbin danmekanismenya, untuk merancang alat turbin angin ini terlebih dahulu dilakukan pengamatan dan pembelajaran dari turbin angin yang sudah ada untuk pencarian data.

2) Metode interview

Metode interview, yaitu suatu metode pengumpulan data dimana penulis mengadakan wawancara secara langsung dengan narasumber yang berkopeten dibidang ini.

3) Studi Literatur

Mempelajari literatur yang membantu dan mendukung proses manufaktur dan perakitan (assembling) turbin angin, mempelajari dasar rancangan elemen mesin, langkah-langkah kinerja dari turbin angin, dan literatur lain yang mendukung.

4) Perencanaan dan Perancangan

Setelah melakukan pencarian data dan pembuatan konsep yang didapat dari literatur studi kepustakaan dan dilihat dari percobaan tentang turbin angin yang sudah ada, maka dapat direncanakan elemen-elemen dari percancangan pembuatan turbin. Perencanaan dan perancang adalah langkah awal dari pembuatan turbin angin ini harus dilakukan dengan benar agar turbin angin yang dibuat dapat bekerja secara maksimal.

5) Pengujian Alat

Setelah alat sudah terebentuk semua maka harus dilakukan pengujian untuk mengetahui apakah alat dapat berfungsi secara maksimal atau tidak. Pengujian alat juga dilakukan untuk mendapatkan data-data sesuai dengan fokus masalah.

\section{HASIL DAN PEMBAHASAN}

\section{Hubungan Torsi (T) Terhadap Putaran (n)}

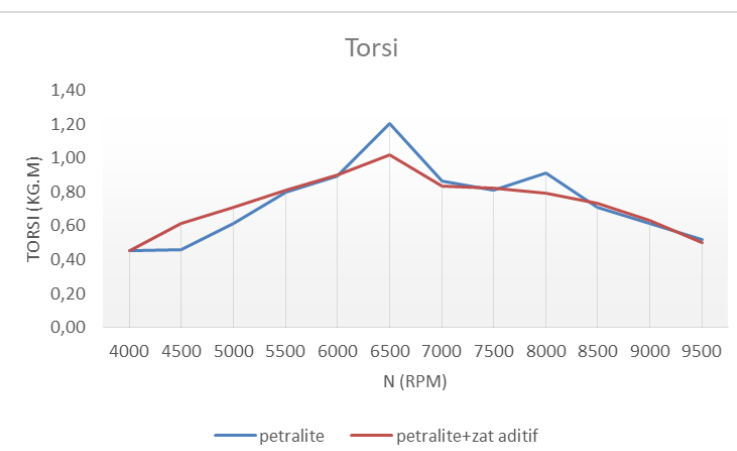

Gambar 1. Grafik Perbandingan Torsi Terhadap Putaran

Dari grafik diatas menunjukkan hubungan torsi terhadap putaran dimana kenaikan torsi seiring dengan meningkatnya putaran untuk setiap konsentrasi. Untuk konsentrasi pertalite $100 \%$ menunjukan bahwa torsi maksimum dicapai adalah $1,2 \mathrm{~kg} . \mathrm{m}$ pada putaran $6500 \mathrm{rpm}$, dan torsi maksimum menggunakan konsentrasi petralite dengan campuran zat aditif adalah 1,02 kg.m yang dicapai pada putaran $6500 \mathrm{rpm}$.

\section{Perbandingan Hubungan Daya (P) Terhadap Putaran (n)}

Dari Gambar 2 menunjukkan hubungan daya terhadap putaran. Untuk konsentrasi petralite $100 \%$ menunjukan bahwa daya maksimum dicapai adalah 10,13 pada putaran 6500, dan Pada konsentrasi petralite dengan campuran zat aditif menunjukan 
bahwa daya maksimum dicapai adalah 10,03 PS pada putaran $6500 \mathrm{rpm}$.

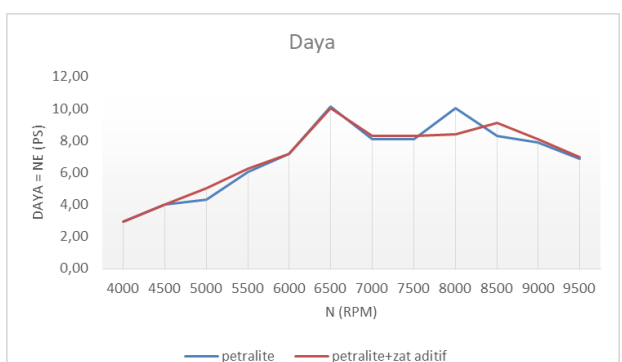

Gambar 2. Grafik Perbandingan Bahan Bakar Terhadap Daya Dan Putaran

Perbandingan Konsumsi Bahan Bakar Terhadap Putaran

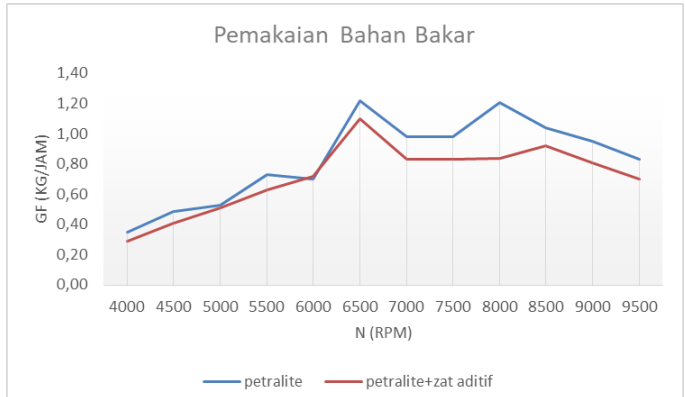

\section{Gambar 3. Grafik Hubungan Konsumsi} Bahan Bakar Terhadap Putaran

Dari Gambar 3 di atas menunjukkan hubungan pemakaian bahan bakar spesifik (Gf) terhadap putaran (n),menunjukkan kenaikan komsumsi bahan bakar spesifik seiring dengan meningkatnya putaran poros untuk setiap konsentrasi. Untuk konsentrasi petralite $100 \%$ menunjukan bahwa pemakaian maksimum adalah $1.22 \mathrm{~kg} / \mathrm{jam}$ pada putaran 6500. Sedangkan untuk konsentrasi maksimum petralite dengan menggunakan campuran zat aditif menunjukan bahwa pemakaian minimum bahan bakar spesifik (Gf) sebesar 1,10 kg/jam pada putaran $6500 \mathrm{rpm}$.

\section{Efisiensi Volumetrik ( $\mathrm{nVol})$}

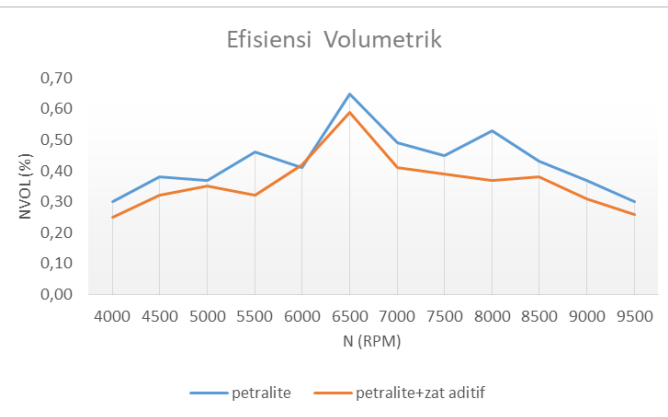

Gambar 4. Grafik Efisiensi Volumetrik
Efisiensi volumetrik adalah salah satu faktor penting dari parameter kinerja mesin pembakaran dalam. Ini adalah rasio ( atau persentase ) dari jumlah udara mengalir masuk ke dalam mesin yang (sebenarnya) / berat udara mengalir masuk kedalam mesin yang (ideal). Secara umum, kebanyakan mesin mencapai efisiensi volumetrik tertinggi di suatu tempat di sekitar nilai torsi puncaknya. Pada konsetrasi menggunakan bahan bakar pertalite nilai efisiensi tertinggi sebesar $18,28 \%$ pada putaran $8000 \mathrm{rpm}$. Untuk konsentrasi menggunakan bahan bakar campuran aditif dengan nilai efisiensi tertinggi sebesar $0,59 \%$ pada putaran $6500 \mathrm{rpm}$.

\section{Tekanan Efektif Rata-Rata Motor (Pe)}

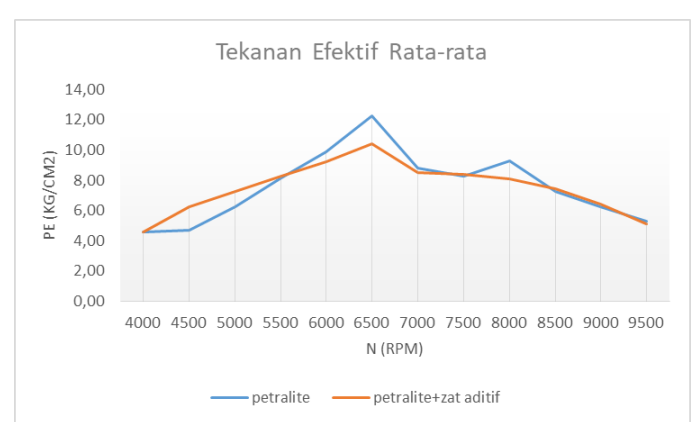

Gambar 5. Grafik Tekanan Efektif Rata-Rata

Grafik di atas memberikan gambaran tentang tekanan efektif rata-rata yang dapat dicapai dengan menggunakan bahan bakar pertalite terjadi pada putaran yang lebih tinggi dibandingkan dengan menggunakan bahan bakar menggunakan bahan bakar campuran aditif, hal tersebut dikarenakan nilai pembakaran menggunakan bahan bakar standar lebih baik dari bahan bakar dengan campuran aditif.

\section{KESIMPULAN}

Dari hasil penelitian yang telah dilakukan pada motor automatic PGM-FI satu silinder $125 \mathrm{cc}$ dapat diambil kesimpulan sebagai berikut :

1. Daya tertinggi pada penggunaan jenis bahan bakar pertalite yaitu 10,13 PS pada putaran mesin 6500 rpm, dan daya tertinggi yang dihasilkan pada penggunaan jenis bahan bakar petralite dengan campuran aditif octane booster 10,03 PS pada putaran mesin $6500 \mathrm{rpm}$. Torsi tertinggi yang dihasilkan oleh petralite yaitu : 1,2 Kg.m pada putaran $6500 \mathrm{rpm}$ dan petralite dengan campuran aditif octane booster sebesar 1,02 Kg.m pada putaran yang sama. Dengan menggunakan petralite dengan campuran aditif octane booster tekanan efektif yang dihasilkan lebih stabil 
dibandingkan dengan menggunakan petralite murni.

2. Pada penggunaan bahan bakar seperti pada grafik 4.3 menunjukan adanya peningkatan jumlah konsumsi bahan bakar seiring meningkatnya putaran rpm pada engine. Pada penggunaan tambahan aditif octane booster terjadi penurunan pada tingkat konsumsi bahan bakar dibandingkan dengan penggunaan bahan bakar petralite murni.

\section{DAFTAR PUSTAKA}

Arismunandar Wiranto. (1988). Penggerak Mula Motor Bakar Torak. Bandung: Penerbit ITB.

Kristanto Philip. (2015). Motor Bakar Torak Teori \& Aplikasinya. Yogyakarta: Penerbit Andi.

Farkhan, 2015, analisis performa mesin menggunakan campuran bahan bakar premium dengan ethanol terhadap daya dan torsi pada toyota kijang innova tipe 1TR-FE, tugas akhir, jurusan D3 teknik mesin fakultas teknik, Universitas Negri Semarang.

Muharam Yuli Prasojo, 2015, Pengaruh penggunaan cdi standar dengan cdi racing menggunakan bahan bakar premium pertamax dan pertamax plus terhadap daya dan torsi motor bensin satu silinder, Skripsi, jurusan S1 teknik mesin fakultas teknik, Universitas Negri Semarang.

Mohammad Saifudin, 2013, sistem bahan bakar pada mio-j ymjet-fi, tugas akhir,

jurusan D3 teknik mesin fakultas teknik, Universitas Negri Semarang.

Sigit Iriyanto, 2008, Analisa performa sepeda motor 4 langkah satu silinder $125 \mathrm{cc}$ terhadap variasi campuran bahan bakar, Skripsi,jurusan S1 teknik mesin fakultas teknik, Universitas Indonesia.

Amrullah, Sungkono, Eko Prastianto, analisis pengaruh penggunaan bahan bakar premium dan pertamax terhadap prestasi mesin. Jurnal Teknik Mesin, Universitas Muslim Indonesia, Teknologi Volume 18 No. 1 April 2018.

Riki Candra Putra, Andri Suhendri. Perbandingan unjuk kerja dan konsumsi bahan bakar antara motor yang mempergunakan koil standar dan busi standar dengan motor yang mempergunakan koil racing dan busi racing menggunakan bahan bakar pertamax. Motor Bakar: Jurnal Teknik Mesin

Teknikmesinzone - langkah kerja motor - Kamis, 20 Agustus 2020 http://teknikmesinzone.blogspot.com/2016/0 9/motor-empat-langkah.html

Yamaha motor - Motor x-ride 125cc - Minggu, 23 Agustus 2020- https://www.yamahamotor.co.id/product/xride/

Andre Dwiky Kurniawan, Semin, 2014, Tjoek Supartijo. Analisa Penggunaan Bahan Bakar Biotehanol Dari Batang Padi Sebagai campuran Pada Bensin. Teknik Sistem Perkapalan. Institut Teknologi Sepuluh November. 